\title{
Editorial
}

\section{How should patients with patent foramen ovale be managed?}

The development of percutaneous devices capable of closing atrial septal defects has led to renewed debate about optimal management of patients with patent foramen ovale (PFO). Echocardiography has made diagnosing PFO routine, but in most patients appropriate management, including the role of device closure, remains a matter of speculation.

\section{Anatomy and prevalence}

During infancy, fibrous adhesions usually seal the atrial septum, but occasionally it does not seal completely, giving rise to a patent foramen ovale (PFO). In some individuals, excess atrial septal tissue in the region of the fossa ovalis causes increased movement of the septum during respiration. When excursion is greater than $10 \mathrm{~mm}$ this appearance is classified as an atrial septal "aneurysm", which can occur in isolation, or in combination with a PFO. ${ }^{1}$

PFO is a common finding in the normal healthy population. A necropsy study of 965 normal human hearts showed an overall prevalence of $27 \%$, with no sex differences, and a mean PFO diameter of $5 \mathrm{~mm} .^{2}$ Small PFO probably close spontaneously throughout adult life, as there is a reduction in prevalence from $34 \%$ in the first three decades compared to $20 \%$ in the ninth and 10 th decades. ${ }^{2}$ Observational echocardiography studies have identified atrial septal aneurysm in about $2-4 \%$ of the normal population, ${ }^{34}$ associated with a PFO in up to $70 \%$ of cases. $^{4}$

\section{Diagnosis}

Transoesophageal echocardiography (TOE) is the investigation of choice for the diagnosis of PFO. Even if the interatrial septum looks normal on two dimensional imaging, colour Doppler may show flow between the atria. Sensitivity is improved by Valsalva and coughing manoeuvres, which transiently increase right atrial pressures, with injection of microbubble contrast agents (agitated saline or gelatine). Passage of microbubbles from right to left atrium within three cardiac cycles usually identifies a PFO. Size is graded as small (up to 5 bubbles), medium (6-25 bubbles) or large (>25 bubbles)..$^{56}$ Together, colour Doppler and contrast TOE have a high sensitivity and specificity for the diagnosis of $\mathrm{PFO} .^{78}$

Transthoracic echocardiography (TTE) with contrast injection can be used to diagnose PFO, but has a sensitivity of up to $80 \%$ compared to TOE. ${ }^{9}$ Thus, a negative TTE does not exclude a PFO, but a diagnostic TTE may avoid the need for a TOE.

Transcranial Doppler sonography after contrast injection is used extensively in anaesthetics, neurology, and vascular surgery for identifying patients with PFO. Characteristic high pitched Doppler signals detected over the middle cerebral artery identify a shunt and sensitivity is increased by the Valsalva manoeuvre. Transcranial Doppler appears to have a similar sensitivity and specificity to TOE for the diagnosis of PFO. ${ }^{10-12}$ However, in one study 4/44 patients with abnormal transcranial Doppler responses had no evi- dence of a cardiac shunt on TOE. ${ }^{13}$ This discrepancy was attributed to the patients performing a more complete Valsalva manoeuvre in the absence of sedation.

\section{Consequences of PFO}

Although PFO is common, adverse consequences arise infrequently. However, when right atrial pressure is increased, right to left interatrial shunting can occur, and deoxygenated blood or emboli ("paradoxical embolism") may enter the systemic circulation. Such changes may occur transiently-for example, during sneezing ${ }^{14}$ or during "Valsalva" manoeuvres such as weightlifting. ${ }^{15}$ Right to left shunting may persist in cases of right ventricular myocardial infarction ${ }^{16}$ (leading to hypoxae$\left.\mathrm{mia}^{17}{ }^{18}\right)$, structural tricuspid valve disease, ${ }^{19}$ or more commonly following acute pulmonary embolism. ${ }^{20}$ In patients with major pulmonary embolism, PFO is associated with a worse prognosis, ${ }^{21}$ and it has been suggested that screening for PFO should be performed in such cases, to help target aggressive treatment. ${ }^{22}$

PFO with significant right to left shunting may have a role in the pathogenesis of decompression illness following sub-aqua dives. It is hypothesised that venous gas bubbles liberated after the diver's rise to the surface may enter the systemic circulation through a PFO and embolise into the central nervous system (CNS) ${ }^{23}$ However, although many divers may have a PFO, few dives are complicated by decompression illness, ${ }^{24}$ and other factors, including pulmonary barotrauma and the CNS response to ischaemic injury, may contribute to the clinical syndrome. ${ }^{23}$

$\mathrm{PFO}$ has been implicated in the pathogenesis of arterial thromboembolism. Direct evidence for this comes from more than 30 case reports of impending paradoxical embolism, in which thrombus was visualised in transit through a $\mathrm{PFO} .^{22}$ Most of these cases presented with acute pulmonary embolism, and systemic arterial embolisation involving limbs, viscera, coronary arteries, or the cerebral circulation.

However, in most patients with possible embolic disease, trans-septal thrombus is not visualised by cardiac imaging. Determining whether paradoxical embolism has occurred through a PFO ideally requires documentation of a "triad" of the PFO, raised right atrial pressure, and a venous source of thrombus. Unfortunately documenting the components of this triad is difficult; venous thrombus was identified in only $10 \%$ of patients with PFO and stroke, ${ }^{9}$ and can be proven in only $50 \%$ of cases of definite pulmonary embolism. ${ }^{25}$ This inability to exclude venous thrombosis has maintained interest in the potentially pathological role of PFO, particularly among young adults with strokes that are unexplained (or "cryptogenic") despite extensive investigation. $^{26}$

Numerous investigators have reported an association between PFO and ischaemic stroke in younger patients. ${ }^{4} 2728$ One retrospective study demonstrated a higher prevalence of PFO in stroke patients than in age matched controls (40\% $v 10 \%)$, and higher still $(54 \%)$ in 26 patients with cryptogenic stroke. ${ }^{27} \mathrm{~A}$ case-control study of patients with cryptogenic stroke used stepwise logistic 
regression analysis to calculate a stroke odds ratio of 3.0 (95\% confidence interval (CI) 1.1 to 8.1 ) for a patient with PFO, an odds ratio of 2.1 (95\% CI 0.4 to 10.4 ) for a patient with atrial septal aneurysm alone, and an odds ratio of 33.3 (95\% CI 4.1 to 270) for a patient with both these abnormalities. ${ }^{4}$ However, contrasting data from a recent prospective study of 42 patients in whom atrial septal aneurysm was identified incidentally ( $56 \%$ with associated PFO), revealed no cerebrovascular events over a mean follow up period of 5.8 years (range 4.7-7.1 years). ${ }^{29}$

Data supporting a pathological role for $\mathrm{PFO}$ in cryptogenic stroke have also come from cerebral imaging. A retrospective analysis showed "embolic-type" cerebral infarcts were more likely in patients with larger PFO (more than $2 \mathrm{~mm}$ diameter).$^{30}$ However, these 95 patients were heterogeneous and patients with a clearly determined cause of stroke had not been excluded.

A single prospective study has demonstrated a correlation between the size of the interatrial shunt and risk of ischaemic stroke. ${ }^{31}$ Patients were divided into two groups and over 21 months follow up, 5/16 patients (mean age 58 years) with large shunts had recurrent neurological events, compared with $0 / 18$ patients (mean age 54 years) with smaller shunts $(p=0.03)$. These events occurred despite antiplatelet or anticoagulant treatment. The definition of a large shunt in this series was detection of more than 20 bubbles in a single video frame without provocative manoeuvres.

\section{Treatment}

Management options include aspirin or warfarin, or both, and closure of the PFO either by open surgery or by percutaneous catheter based devices. There have been no prospective randomised trials of these treatments and published event rates in uncontrolled series vary considerably (table 1).

Limited data exist on recurrent event rates in young stroke patients with PFO treated medically. In a retrospective study of aspirin or warfarin treatment, 0/69 patients with PFO alone, $1 / 25$ patients with isolated atrial septal aneurysm, and $5 / 38$ patients with both abnormalities had a recurrent stroke or transient ischaemic attack (TIA) during a two year period. ${ }^{32}$ A similar study of 140 patients with PFO followed for a mean of three years reported a recurrent stroke rate of $1.9 \%$ per annum. ${ }^{33}$ However, in both of these studies event numbers were too small to differentiate between treatments, and subclinical ischaemic events could have been missed.

Data on long term outcome following surgical PFO closure is limited to small uncontrolled case series. ${ }^{34-37}$ Follow up ranged from seven months to four years, and pharmacological treatment was not controlled, but included aspirin or warfarin in about half the patients. No operative complications were reported and the recurrent event rate varied from $0 \%{ }^{36}$ to $19.5 \% .{ }^{34} \mathrm{~A}$ recent retrospective analysis of 91 patients who had surgical closure of a PFO following a cerebral infarct reported a recurrent TIA rate of $16 \%$ over four years, despite TOE demonstration of an intact repair in each case. ${ }^{38}$

More recently, catheter based devices have been used to close atrial septal defects (ASD) and PFO. A multicentred observational study using a double umbrella type closure system in 154 consecutive patients with ASD and in 46 patients with PFO reported procedure failure in 26 patients, and subsequent surgical removal of the device in a further 12 patients. ${ }^{39}$ During a mean follow up of 17 months, 1/46 patients with PFO had a recurrent neurological event. Improved procedural results were obtained with a different self expanding double disk device (Amplatzer septal occluder) in 100 consecutive patients
Table 1 Recurrent thromboembolic event rates with different patent foramen ovale (PFO) management strategies

\begin{tabular}{|c|c|c|}
\hline Management strategy & $\begin{array}{l}\text { Annual recurrent } \\
\text { event rate }\end{array}$ & References \\
\hline Aspirin or warfarin & $1.9-14 \%$ & $\begin{array}{l}\text { Stone } \text { et } a l^{11} \\
\text { Mas and Zuber } \\
\text { Bogousslavsky et } a l^{33}\end{array}$ \\
\hline Surgical PFO closure & $0-19.5 \%$ & $\begin{array}{l}\text { Homma et } a l^{34} \\
\text { Devuyst et } a l^{36} \\
\text { Dearani et } a l^{38}\end{array}$ \\
\hline Percutaneous PFO closure & $3.4 \%$ & Windecker et $a l^{41}$ \\
\hline
\end{tabular}

(seven with PFO). ${ }^{40}$ Deployment failures occurred in only seven cases, with one device embolisation, and four other complications, including a probable TIA. However, by follow up at three months, 92/93 successfully treated defects remained closed. A recent prospective but uncontrolled study of percutaneous PFO closures in 80 cryptogenic stroke patients using various devices reported a procedural success rate of $98 \%$, with a $10 \%$ complication rate (including cardiac tamponade, air embolisation and device embolisation). ${ }^{41}$ However, a residual interatrial shunt was detected by TOE in $21 / 78$ patients, and over a mean follow up of 1.6 years (range $0.1-5$ years) the average annual recurrent thromboembolic event rate was $3.4 \%$. Of the eight patients with recurrent events, three had no evidence of a residual shunt.

\section{Conclusions}

PFO is common enough in the normal population to be considered an anatomical variant, and for any individual the absolute risk of adverse events from a PFO is clearly very small. When right atrial pressure is increased, right to left shunting is possible, and this may exacerbate hypoxaemia in pulmonary embolism and right ventricular infarction. There are also data to suggest PFO may have a role in decompression illness in divers.

When venous thrombosis coexists with raised right atrial pressure, paradoxical embolism through a PFO can occur, and this may result in stroke or peripheral arterial emboli. However, in most cases of cryptogenic stroke with PFO there is no definite evidence of paradoxical embolism. In these cases, percutaneous or surgical PFO closure to prevent recurrent thromboembolic events is not a proven strategy, as event rates following intervention appear similar to those achieved with medical treatment, and there is an additional procedural risk.

It seems likely that within the population of patients with PFO and embolism there are further mechanisms, such as occult clotting abnormalities, which may be responsible for recurrent events. At present, closure of large PFO in patients with cryptogenic stroke (passage of more than 20 microbubbles without provocative manoeuvres) appears to be reasonable if recurrent symptoms occur despite optimal medical treatment, or if all the elements of the triad necessary for paradoxical embolism (PFO, venous thrombosis, and increased right heart pressures) are clearly documented. But patients undergoing closure of PFO should be warned that even despite apparently successful intervention, their risk of recurrent events remains elevated and that medical treatment should probably be continued lifelong.

NICHOLAS ALP

NIGEL CLARKE

Department of Cardiology, ADRIAN P BANNING

Fohn Radcliffe Hospital,

Headley Way,

Oxford OX3 9DU, UK

adrian.banning@orh.anglox.nhs.uk 
1 Pearson AC, Nagelhout D, Castello R, et al. Atrial septal aneurysm and stroke: a transesophageal echocardiographic study. $\mathcal{F}$ Am Coll Cardio $1991 ; 18 \cdot 1223-9$

2 Hagen PT, Scholz DG, Edwards WD. Incidence and size of patent foramen ovale during the first 10 decades of life: an autopsy study of 965 normal hearts. Mayo Clin Proc 1984;59:17-20.

3 Olivares-Reyes A, Chan S, Lazar EJ, et al. Atrial septal aneurysm: a new classification in two hundred five adults. $\mathcal{F} \mathrm{Am}$ Soc Echocardiogr 1997;10:644-56.

4 Cabanes L, Mas JL, Cohen A, et al. Atrial septal aneurysm and patent foramen ovale as risk factors for cryptogenic stroke in patients less than 55 years of age. A study using transesophageal echocardiography. Stroke 1993; 24:1865-73.

5 Webster MW, Chancellor AM, Smith HJ, et al. Patent foramen ovale in young stroke patients. Lancet 1988;ii:11-12.

6 Van Camp G, Schultze D, Cosyns B, et al. Relation between patent foramen ovale and unexplained stroke. Am f Cardiol 1993;71:596-8.

7 Schneider B, Zienkiewicz T, Jansen V, et al. Diagnosis of patent foramen ovale by trans-oesphageal echocardiography and correlation with autopsy ovale by trans-oesphageal echocardiograph

8 Sun JP, Stewart WJ, Hanna J, et al. Diagnosis of patent foramen ovale by contrast colour Doppler trans-oesophageal echocardiography: relation to atrial size. Am Heart f 1996;131:239-44.

9 Lethen H, Flaschkampf FA, Schneider R, et al. Frequency of deep vein thrombosis in patients with patent foramen ovale and ischemic stroke or transient ischemic attack. Am $\mathcal{F}$ Cardiol 1997;80:1066-9.

10 Jauss M, Kaps M, Keberle M, et al. A comparison of transoesophageal echocardiography and transcranial Doppler sonography with contrast medium for the detection of patent foramen ovale. Stroke 1994;25:1265-7.

11 Droste DW, Reisener M, Kemeny V, et al. Contrast transcranial doppler ultrasound in the detection of right to left shunts. Stroke 1999;30:1014-18.

12 Job FP, Ringelstein EB, Grafen Y, et al. Comparison of transcranial contrast Doppler sonography and transoesophageal contrast echocardiography for the detection of patent foramen ovale in young stroke patients. Am f Cardiol 1994;74:381-4.

13 Schwarze JJ, Sander D, Kukla C, et al. Methodological parameters influence the detection of right-to-left shunts by contrast transcranial Doppler ultrasonography. Stroke 1999;30:1234-9.

14 Matthew TC, Ramsaran EK, Aragam JR. Impending paradoxical embolism in acute pulmonary embolism: diagnosis by trans-oesophageal echocardioin acute pulmonary embolism: diagnosis by trans-oesophageal echocardio-

15 Sweeny BJ, Rossor MN. Medial medullary syndrome associated with patent Sweeny BJ, Rossor MN. Medial medullary syndrome associa

16 Morris AL, Donen N. Hypoxia and intracardiac right-to-left shunt. Arch Intern Med 1978;138:1405-6.

17 Bansal RC, Marsa RJ, Holland D, et al. Severe hypoxia due to shunting through a patent foramen ovale: a correctable complication of right ventricular infarction. F Am Coll Cardiol 1985;5:188-92.

18 Silver MT, Lieberman EH, Thibault GE. Refractory hypoxaemia in inferior myocardial infarction from right to left shunting through a patent foramen ovale: a case report and review of the literature. Clin Cardiol 1994;17:62730

19 Corrin B. Paradoxical embolism. Br Heart f 1964;26:549-53.

20 Ward R, Jones D, Haponik EF. Paradoxical embolism: an under-recognized problem. Chest 1995;108:549-58.

21 Kasper W, Geibel A, Tiede N. Patent foramen ovale in patients with haemodynamically significant pulmonary embolism. Lancet 1992;340:561-4.

22 Meacham RR, Headley AS, Bronze MS, et al. Impending paradoxical embolism. Arch Intern Med 1998;158:438-48.

23 Wilmshurst PT, Byrne JC, Webb-Peploe MM. Relation between interatrial shunts and decompression sickness in divers. Lancet 1989;ii:1302-6.

24 Wilmshurst PT, Treacher DF, Crowther A, et al. Effects of a patent foramen ovale on arterial saturation during exercise and on cardiovascular responses to deep breathing, Valsalva manoeuvre, and passive tilt: relation to history or decompression illness in divers. Br Heart f 1994;71:229-31.

25 Rosenow EC, Osmundson PJ, Brown ML. Pulmonary embolism. Mayo Clin Proc 1981;56:161-78.

26 Hart RG, Miller VT. Cerebral infarction in young adults: a practical approach. Stroke 1983;14:110-14.

27 Lechat P, Mas JL, Lascault G, et al. Coagulation abnormalities in adults with cryptogenic stroke and patent foramen ovale. F Neurol Sci 1998;160:15860 .

28 de Belder MA, Tourikis L, Leech G, et al. Risk of patent foramen ovale for thromboembolic events in all age groups. Am f Cardiol 1992;69:1316-20.

29 Burger AJ, Sherman HR, Charlamb MJ. Low incidence of embolic strokes with atrial septal aneurysms: a prospective, long-term study. Am Heart $\mathcal{f}$ 2000;139:149-52.

30 Steiner MM, Di Tullio MR, Rundek T, et al. Recurrent cerebrovascular events in patients with patent foramen ovale, atrial septal aneurysm, or both and cryptogenic stroke or transient ischemic attack. French study group on patent foramen ovale and atrial septal aneurysm. Am Heart f 1995; 130: $1083-8$

31 Stone DA, Godard J, Corretti MC, et al. Patent foramen ovale: sssociation between the degree of shunt by contrast transesophageal echocardiography and the risk of future ischemic neurologic events. Am Heart $\mathcal{F}$ 1996;131:158-61.

32 Mas JL, Zuber M. Recurrent cerebrovascular events in patients with patent foramen ovale, atrial septal aneurysm, or both and cryptogenic stroke or transient ischemic attack. Am Heart f 1995;130:1083-8.

33 Bogousslavsky J, Garazi S, Jeanrenaud X, et al. Stroke recurrence in patient with patent foramen ovale: the Lausanne study. Lausanne stroke with paradoxical embolism study group. Neurology 2000;46:1301-5.
34 Homma S, Di Tullio MR, Sacco RL, et al. Surgical closure of patent foramen ovale in cryptogenic stroke patients. Stroke 1997;28:2376-81.

35 Harvey JR, Teague SM, Anderson JL, et al. Clinically silent atrial septal defects with evidence for cerebral embolisation. Ann Intern Med 1986;105: 695-7.

36 Devuyst G, Bogousslavsky J, Ruchat P, et al. Prognosis after stroke followed by surgical closure of patent foramen ovale: a prospective follow up study with brain MRI and simultaneous trans-oesphageal and transcranial Doppler ultrasound. Neurology 1996;47:1162-6.

37 Ruchat P, Bogousslavsky J, Hurni M, et al. Systematic surgical closure of patent foramen ovale in selected patients with cerebrovascular events due to paradoxical embolism. Early results of a preliminary study. Eur 7 Cardiothorac Surg 1997;11:824-7.

38 Dearani JA, Ugurlu BS, Danielson GK, et al. Surgical patent foramen ovale closure for prevention of paradoxical embolism-related cerebrovascular ischemic events. Circulation 1999;100:II171-5.

39 Sievert H, Babic UU, Hausdorf G, et al. Transcatheter closure of atrial septal defect and patent foramen ovale with the ASDOS device (a multicentre European trial). Am f Cardiol 1998;82:1405-13.

40 Chan KC, Godman MJ, Walsh K, et al. Transcatheter closure of atrial septal defect and interatrial communications with a new self expanding nitinol double disc device (Amplatzer septal occluder): multicentre UK experience. Heart 1999;82:300-6.

41 Windecker S, Wahl A, Chatterjee T, et al. Percutaneous closure of patent foramen ovale in patients with paradoxical embolism : long-term risk of recurrent thromboembolic events. Circulation. 2000;101:893-8.

\section{WEB TOP 10}

\section{www.heartinl.com}

These articles scored the most hits on Heart's web site during December 2000

1 Treatment strategies for heart failure: $\beta$ blockers and antiarrhythmics

AP Maggioni

January 2001;85:97-103 (Education in Heart)

2 Hibernating myocardium

$R$ Schulz, G Heusch

December 2000;84:587-94 (Review)

3 Joint British recommendations on prevention of coronary heart disease in clinical practice December 1998;80(suppl 2):S1-29

4 Acute myocardial infarction: failed thrombolysis $M A$ de Belder January 2001;85:104-12 (Education in Heart)

5 Clinical anatomy of the aortic root $R H$ Anderson December 2000;84:670-3 (Education in Heart)

6 Blood pressure measurement is changing! E O'Brien January 2001;85:3-5 (Editorial)

7 Vascular and valvar calcification: recent advances A Farzaneh-Far, D Proudfoot, C Shanahan, PL Weissberg January 2001;85:13-17 (Review)

8 Comparative accuracy of cardiovascular risk prediction methods in primary care AF fones, $\mathcal{F}$ Walker, $C$ ferves, FL Game, WA Bartlett, T Marshall, GR Bayly

January 2001;85:37-43 (Cardiovascular medicine)

9 Haemodynamic calculations in the catheter laboratory FL Wilkinson

January 2001;85:113-20 (Education in Heart)

10 Baseline predictors of tolerability to carvedilol in patients with chronic heart failure

H Krum, D Ninio, P MacDonald

December 2000;84:615-19 (Cardiovascular medicine) 